\title{
openheart Management of patients with severe aortic stenosis in the TAVI-era: how recent recommendations are translated into clinical practice
}

\begin{abstract}
Alexander Lauten, ${ }^{1}$ Tanja K Rudolph, ${ }^{2}$ David Messika-Zeitoun (D) , ${ }^{3}$ Jeetendra Thambyrajah, ${ }^{4}$ Antonio Serra, ${ }^{5}$ Eberhard Schulz, ${ }^{6}$ Norbert Frey, Jiri Maly, ${ }^{8,9}$ Marco Aiello, ${ }^{10}$ Guy Lloyd, ${ }^{11}$ Alessandro Santo Bortone, ${ }^{12}$ Alberto Clerici, ${ }^{13}$ Georg Delle-Karth, ${ }^{14}$ Johannes Rieber, ${ }^{15}$ Ciro Indolfi, ${ }^{16}$ Massimo Mancone, ${ }^{17}$ Loic Belle, ${ }^{18}$ Martin Arnold, ${ }^{19}$ Berto J Bouma, ${ }^{20}$ Matthias Lutz, ${ }^{7}$ Cornelia Deutsch, ${ }^{21}$ Jana Kurucova, ${ }^{22}$ Martin Thoenes, ${ }^{23}$ Peter Bramlage (D) ,21 Richard Paul Steeds (D) ${ }^{24}$
\end{abstract}

To cite: Lauten A, Rudolph TK, Messika-Zeitoun D, et al. Management of patients with severe aortic stenosis in the TAVI-era: how recent recommendations are translated into clinical practice. Open Heart 2021;8:e001485. doi:10.1136/ openhrt-2020-001485

Received 13 0ctober 2020 Revised 2 December 2020 Accepted 21 December 2020
Check for updates

(c) Author(s) (or their employer(s)) 2021. Re-use permitted under CC BY-NC. No commercial re-use. See rights and permissions. Published by BMJ.

For numbered affiliations see end of article.

Correspondence to Dr Peter Bramlage; peter. bramlage@ippmed.de

\section{ABSTRACT}

Objective Approximately $3.4 \%$ of adults aged $>75$ years suffer from aortic stenosis (AS). Guideline indications for aortic valve replacement (AVR) distinguish between patients with symptomatic and asymptomatic severe AS. The present analysis aims to assess contemporary practice in the treatment of severe AS across Europe and identify characteristics associated with treatment decisions, namely denial of AVR in symptomatic patients and assignment of asymptomatic patients to AVR. Methods Participants of the prospective, multinational IMPULSE database of patients with severe AS were grouped according to AS symptoms, and stratified into subgroups based on assignment to/denial of AVR. Results Of 1608 symptomatic patients, $23.8 \%$ did not undergo AVR and underwent medical treatment. Denial was independently associated with multiple factors, including severe frailty $(p=0.024)$; mitral $(p=0.002)$ or tricuspid ( $\mathrm{p}=0.004)$ regurgitation grade III/IV, and the presence of renal impairment $(p=0.017)$. Of 392 asymptomatic patients, $86.5 \%$ had no prespecified indication for AVR. Regardless, $36.3 \%$ were assigned to valve replacement. Those with an indexed aortic valve area (AVA; $p=0.045$ ) or left ventricular ejection fraction (LVEF; $p<0.001)$ below the study median; or with a left ventricular end systolic diameter above the study median $(p=0.007)$ were more likely to be assigned to AVR.

Conclusions There may be considerable discrepancies between guideline-based recommendations and clinical practice decision-making in the treatment of AS. It appears that guidelines may not fully capture the complete clinical spectrum of patients with AS. Thus, there is a need to find ways to increase their acceptance and the rate of adoption.

\section{INTRODUCTION}

Recent recommendations on the treatment of aortic stenosis (AS) distinguish between

\section{Key questions}

What is already known about this subject?

- In 2012, the European Society of Cardiology produced guidelines that included a class I recommendation for aortic valve replacement in all patients presenting with symptomatic aortic stenosis (AS) These guidelines were updated in 2017 to include all patients with symptomatic AS with high-gradient AS or low-flow, low-gradient AS, a reduced left ventricular ejection fraction and evidence of contractile reserve.

What does this study add?

- Our study assessed the contemporary decisionmaking process for the treatment of patients with severe AS across European treatment centres. We showed that $23.8 \%$ of patients with symptomatic AS did not undergo treatment and treatment denial was associated with severe patient frailty, mitral/tricuspid regurgitation grade III/IV and renal impairment. Conversely, $36.3 \%$ of patients with no prespecified indication for aortic valve replacement were assigned treatment.

How might this impact on clinical practice?

- There appears to be discrepancies between guideline-based recommendations and clinical practice decision-making for treatment of patients with severe AS and a significant percentage of symptomatic patients with severe AS are not being offered life-saving treatment. Guidelines may not fully capture the complete clinical spectrum of patients with AS. Thus, there is a need to find ways to increase their acceptance and the rate of adoption.

patients with symptomatic and asymptomatic severe AS. The 2012 European Society of Cardiology guidelines featured a class-I 
recommendation for aortic valve replacement (AVR; either surgical aortic valve replacement (SAVR) or transcatheter aortic valve implantation (TAVI)) in all patients presenting with symptoms. ${ }^{1}$ This was updated in 2017 to include all symptomatic patients with high-gradient AS or low-flow, low-gradient AS, a reduced left ventricular ejection fraction (LVEF) and evidence of contractile reserve. ${ }^{2}$ A class IIa recommendation remains for those with low-flow, low-gradient AS, a reduced LVEF and no flow reserve, and those with a paradoxical low-flow lowgradient $\mathrm{AS}^{2}{ }^{2}$ In patients with asymptomatic AS, AVR should be performed in patients with a LVEF $<50 \%$ and a pathological exercise test. ${ }^{12}$ AVR is also recommended in asymptomatic patients with a peak transvalvular velocity $\left(\mathrm{V}_{\max }\right)$ of $>5.5 \mathrm{~m} / \mathrm{s}^{12}$ and/or severe pulmonary hypertension. ${ }^{2}$ Generally, a careful risk-benefit analysis by the heart team is advocated prior to AVR in any asymptomatic individual due to recent evidence of a potential benefit of AVR versus medical therapy in asymptomatic patients. ${ }^{3}$ While guidelines recommend best clinical practice according to the available evidence, real-world deviations are known to occur. Furthermore, contemporary data on the real-world management of patients with AS are scarce. Historical data demonstrated that $33 \%-41 \%$ of patients did not undergo SAVR in the past-despite severe symptomatic AS. ${ }^{45}$ Recently, the widespread availability of TAVR has opened a less invasive treatment option for higher risk patients and the process of decisionmaking within the heart team approach has changed in many European centres. It is timely, therefore, to assess the contemporary practice of decision-making in patients with severe AS in centres across Europe in the era of interdisciplinary TAVI treatment. The present analysis aims to explore the characteristics of patients with severe AS with unusual treatment decisions, namely severe symptomatic patients did not undergo AVR and asymptomatic patients assigned to AVR, and to identify potential reasons for it.

\section{METHODS}

Originally designed as part of a quality-of-care initiative, IMPULSE is a prospective, multinational registry of patients with severe AS across Europe. It was funded by Edwards Lifesciences (Nyon, Switzerland) and sponsored by the Institute for Pharmacology and Preventive Medicine (Cloppenburg, Germany). The authors are solely responsible for the design and conduct of this study, all study analyses and drafting and editing of the paper.

The rationale and methodology of the registry has been previously described. ${ }^{6-8}$ Patients were enrolled between March 2015 and April 2017 at 23 centres across nine European countries (Austria, Czech Republic, France, Germany, Italy, the Netherlands, Spain, Switzerland and the UK). All sites offered the full range of treatment options for AS, including surgical and transcatheter procedures. All patients provided their written informed consent to participate.
On a centre basis, consecutive patients aged over 18 years being diagnosed with severe AS (symptomatic or asymptomatic) defined as an aortic valve area (AVA) $<1$ $\mathrm{cm}^{2}$, indexed $\mathrm{AVA}<0.6 \mathrm{~cm}^{2} / \mathrm{m}^{2}, \mathrm{~V}_{\max }>4 \mathrm{~m} / \mathrm{s}$, or mean transvalvular gradient $>40 \mathrm{~mm} \mathrm{Hg}$ following echocardiography were included. Prior AVR recipients were excluded.

Details were documented by each centre (echocardiographer or a nurse under their supervision) and included patient demographics, medical history, disease characteristics and symptoms at presentation (chest pain, shortness of breath and/or dizziness on exertion/syncope) were entered into an electronic case report form. Canadian Cardiovascular Society-defined angina class III/IV and New York Heart Association (NYHA) functional class III/ IV were also recorded. Patients were defined 'symptomatic' if they presented with either chest pain, shortness of breath and/or dizziness on exertion/syncope. Echocardiographic parameters (eg, mean pressure gradient (MPG) and AVA) were documented for each patient, as was the presence of concomitant valve disease or regurgitation. As an indicator of surgical risk, a EuroSCORE II value was calculated for each patient. Frailty was defined as 'none' (able to walk five metres in under 6 s plus independent activities of daily living (ADL) - wash, dress, feed, toilet), "mild" (unable to walk $5 \mathrm{~m}$ in under $6 \mathrm{~s}$ or fails to perform one ADL) or 'severe' (indicated by an inability to perform two or more ADL). ${ }^{9}$ Heart teams were involved in the AVR decision in the participating centres, respectively. These teams were established by each centre leveraging the expertise of cardiologists, cardiac surgeons, imaging specialists, anaesthesiologists and other if needed.

Data are presented descriptively, with continuous variables given as means with SD and categorical variables presented as absolute values with percentages (\%). Group comparisons were made using a Pearson's $\chi^{2}$ or Fisher's exact test for categorical variables and a t-test or Mann-Whitney-Wilcoxon test for continuous variables. Separate logistic regression analyses were carried out to determine baseline variables associated with AVR denial in symptomatic patients and AVR assignment in asymptomatic patients. In the former case and according to the findings of the univariate analysis, multivariateOR, 95\% $\mathrm{CI}$ and $\mathrm{p}$ values were adjusted for age, severe frailty, renal insufficiency, chronic obstructive pulmonary disease (COPD), $\mathrm{V}_{\max }$, mean AV gradient, LVEF, mitral regurgitation grade III/IV and tricuspid regurgitation grade III/IV. In the latter case, these parameters were adjusted for age, diabetes, atrial fibrillation, mean AV gradient, LVEF, pulmonary artery systolic pressure (PASP), aortic regurgitation grade III/IV and mitral regurgitation grade III/IV. All continuous variables were converted to binary predictors for regression analysis, taking the median of the overall study population as a cut-off.

All statistical analysis was performed using SPSS V.24.0 (IBM Corp.), with a p value of $<0.05$ considered statistically significant. 


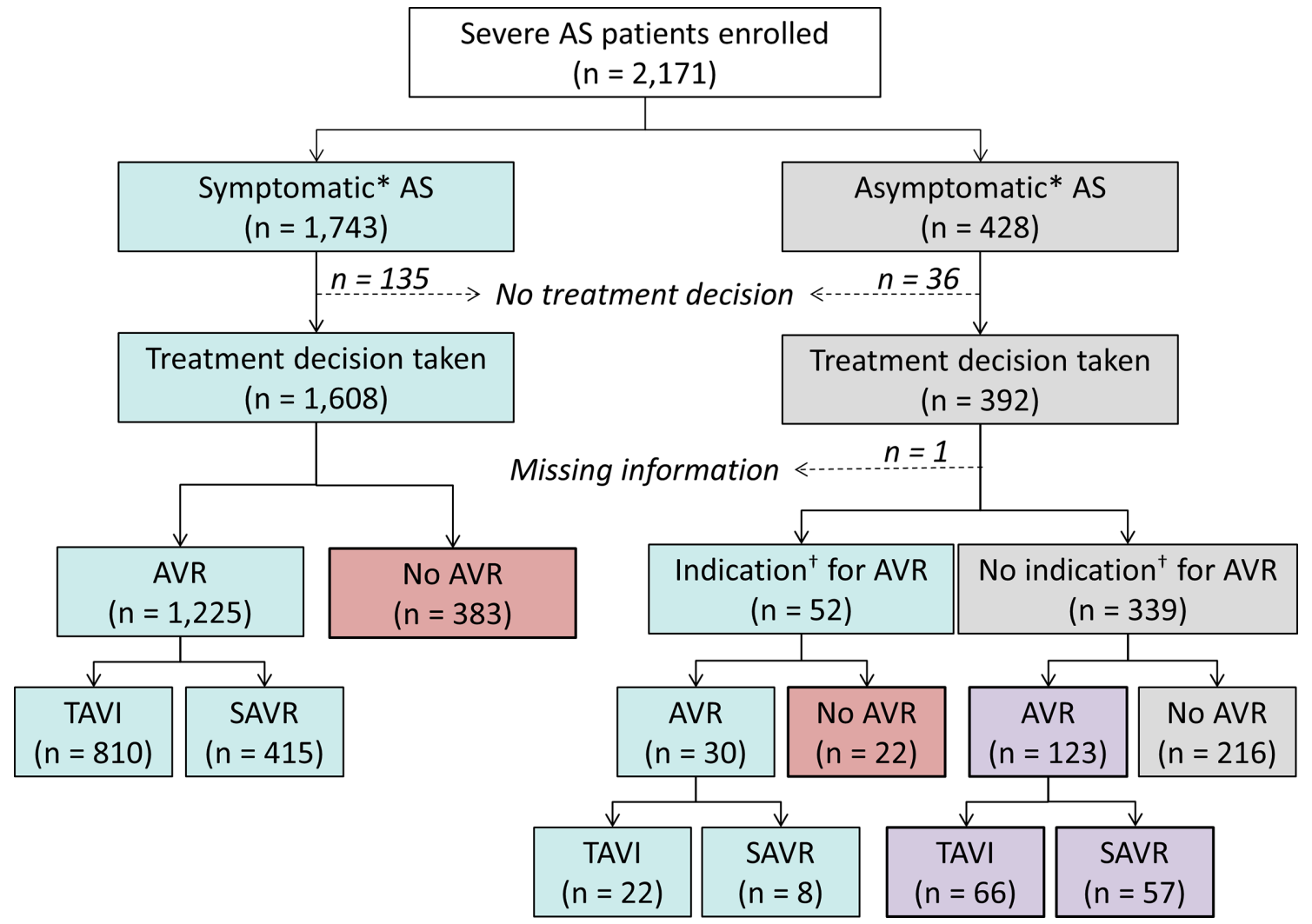

Figure 1 Patient flow. AS, aortic stenosis; AVR, aortic valve replacement (surgical or transcatheter). *Symptomatic defined as having $\geq 1$ of the following (presumed to be AS-related): chest pain, shortness of breath, dizziness on exertion/ syncope. ${ }^{\dagger}$ According to 2017 European guideline recommendations. SAVR, surgical aortic valve replacement.

\section{RESULTS}

A total of 2171 patients were enrolled in the registry, of which 1743 were symptomatic and 428 asymptomatic at presentation (figure 1).

Symptomatic patients who were assigned to medical treatment were slightly older and had a higher mean EuroSCORE II compared with those assigned to AVR, with a higher proportion being severely frail and assessed to have a reduced life expectancy at baseline (table 1). Renal insufficiency and COPD were also more common among those that did not undergo AVR. In symptomatic patients, shortness of breath was the most common symptom recorded with slightly higher rates in those with an AVR (92.7\%) than in those without (86.2\%). Other symptoms, such as dizziness/syncope and chest pain, were equally frequent in those with or without an intervention (figure 2A). Medically treated symptomatic patients had a larger indexed AVA, lower $\mathrm{V}_{\max }$, lower mean AV gradient and higher LVEF; however, mitral and tricuspid regurgitation grade III/IV were more frequent among those that did not undergo AVR, as was the combination of an $\mathrm{AVA}<1 \mathrm{~cm}^{2}$ plus a mean AV gradient $<40$ $\mathrm{mm} \mathrm{Hg}$ (table 2). A definitive decision for either medical treatment or AVR was made in 1608 (92.3\%) of symptomatic patients: 1225 of these patients were assigned to any AVR (810 TAVI and 415 SAVR) and the rest assigned to medical treatment (figure 1). The decisions not to perform AVR despite symptomatic AS were made by a cardiologist in $50.9 \%$ and requested by the patient in $15.4 \%$. A heart team was involved in a 'no AVR' decision in $17.8 \%$ of cases (figure 2). Conversely, the decision to perform AVR in symptomatic patients was made by the heart team in the majority of cases $(68.2 \%)$. The proportion of symptomatic patients with a class I $(95.0 \%$ vs $94.4 \%)$ or class II $(5.0 \%$ vs $5.6 \%)$ indication for AVR did not differ between those that did not undergo and those assigned to AVR ( $p=0.168)$. In a multivariate analysis, the referral by a cardiologist, shortness of breath, NYHA class III/IV and indexed AVA $\leq 0.39 \mathrm{~cm}^{2} / \mathrm{m}^{2}$, an LVEF $\leq 58 \%$ were associated with a reduced rate of AVR denial (table 3 ). On the other hand, age $>80$ years, severe frailty, renal impairment, mitral regurgitation grade III/IV, tricuspid regurgitation grade III/IV and interventricular septum $>13.3 \mathrm{~mm}$ were all associated with an increased risk of AVR denial.

The baseline characteristics of asymptomatic patients assigned to AVR were comparable to those assigned to medical treatment (table 1). In patients undergoing medical treatment, diabetes was more frequent but it did not reach statistical significance. Asymptomatic patients assigned to AVR had a smaller indexed AVA and a higher $\mathrm{V}_{\max }$ (table 2). Mean LVEF was slightly lower (although still within the normal range) and PASP was significantly higher in patients assigned to medical treatment. A definitive treatment decision was made in 392 asymptomatic patients $(91.6 \%)$; 52 of these 392 patients 
Table 1 Baseline characteristics

\section{Symptomatic* patients with treatment decision $(n=1608)$}

\begin{tabular}{|c|c|c|c|c|c|c|}
\hline & & & & \\
\hline & $\begin{array}{l}\text { Assigned to AVR } \\
n=1225 \\
n(\%) \text { or } \\
\text { mean } \pm S D\end{array}$ & $\begin{array}{l}\text { Denied AVR } \\
\mathrm{n}=383 \\
\mathrm{n}(\%) \text { or } \\
\text { mean } \pm \text { SD }\end{array}$ & $P$ value & $\begin{array}{l}\text { No AVR } \\
n=238 \\
n(\%) \text { or } \\
\text { mean } \pm S D\end{array}$ & $\begin{array}{l}\text { Assigned to } \\
\text { AVR } \\
n=154 \\
n(\%) \text { or } \\
\text { mean } \pm S D\end{array}$ & $P$ value \\
\hline Age (years) & $77.7 \pm 9.4$ & $79.8 \pm 9.9$ & $<0.001$ & $75.4 \pm 11.3$ & $74.8 \pm 10.7$ & 0.633 \\
\hline Female gender & $600 / 1225$ (49.0) & 198/383 (51.7) & 0.353 & 93/238 (39.1) & 63/154 (40.9) & 0.717 \\
\hline $\mathrm{BMI}\left(\mathrm{kg} / \mathrm{m}^{2}\right)$ & $27.6 \pm 5.2$ & $27.1 \pm 5.8$ & 0.116 & $27.3 \pm 5.0$ & $26.7 \pm 5.2$ & 0.206 \\
\hline Severe frailty & $41 / 1221(3.4)$ & 28/371 (7.5) & 0.001 & $10 / 229(4.4)$ & 4/154 (2.6) & 0.366 \\
\hline EuroSCORE II (\%) & $4.1 \pm 4.5$ & $4.8 \pm 6.2$ & 0.047 & $1.9 \pm 1.7$ & $2.2 \pm 2.6$ & 0.243 \\
\hline \multicolumn{7}{|l|}{ Comorbidity } \\
\hline Renal insufficiency† & 287/1109 (25.9) & $126 / 341(37.0)$ & $<0.001$ & 39/204 (19.1) & $21 / 145(14.5)$ & 0.258 \\
\hline COPD & 138/1225 (11.3) & 60/383 (15.7) & 0.022 & 9/236 (3.8) & 8/154 (5.2) & 0.514 \\
\hline Diabetesł & 108/1225 (8.8) & $35 / 383(9.1)$ & 0.847 & 18/236 (7.6) & $5 / 154(3.2)$ & 0.073 \\
\hline $\mathrm{AF}$ & $173 / 1140$ (15.2) & 59/337 (17.5) & 0.301 & 21/208 (10.1) & 19/144 (13.2) & 0.368 \\
\hline Endocarditis & $4 / 1225(0.3)$ & $4 / 383(1.0)$ & 0.098 & 2/236 (0.8) & $0 / 154(0.0)$ & 0.521 \\
\hline Previous cardiac surgery & $88 / 1225(7.2)$ & $34 / 383(8.9)$ & 0.275 & $14 / 237(5.9)$ & 4/154 (2.6) & 0.127 \\
\hline 2 -year life expectancy $<25 \% \S$ & $80 / 817(9.8)$ & $41 / 275(14.9)$ & 0.019 & $4 / 150(2.7)$ & $5 / 104(4.8)$ & 0.493 \\
\hline
\end{tabular}

*Symptomatic defined as having $\geq 1$ of the following (presumed to be AS-related): chest pain, shortness of breath, dizziness on exertion/ syncope.

†Creatinine clearance rate $<50 \mathrm{~mL} / \mathrm{min}$ or dialysis.

†Insulin dependent.

$\S 2$-yearlife expectancy $<25 \%$ was assessed by the dedicated nurses and physicians.

$\mathrm{AF}$, atrial fibrillation; AVR, aortic valve replacement; BMI, body mass index; COPD, chronic obstructive pulmonary disease.

had an indication for AVR according to guideline-based criteria (2017: LVEF $<50 \%$, Vmax $>5.5 \mathrm{~m} / \mathrm{s}$, pulmonary hypertension $>60 \mathrm{~mm} \mathrm{Hg}$ ), though such a procedure was planned in just 30 cases (22 were scheduled for TAVI, 8 for SAVR) (figure 1). Of the remaining 339 patients with no prespecified indication for AVR, 123 were assigned to TAVI or SAVR. The heart team was responsible for the majority of AVR assignments in asymptomatic patients $(53.9 \%)$, while cardiologists were responsible for the majority of the decisions not to perform AVR (68.5\%) (figure 3). Patients undergoing AVR had a guidelineconfirming indication in $18.3 \%$ (guidelines from 2012) and $19.6 \%$ (guidelines from 2017) of cases. LVEF $<50 \%$ was the most common reason $(15.3 \%)$ named as a reason for the intervention. Conversely, this means that between $80.4 \%$ and $81.7 \%$ of those undergoing AVR had no guideline-based indication. On the other hand, $8.4 \%$ and 9.2\% patients not undergoing AVR had a guideline-based indication. An indexed AVA, a LVEF below the median of the study population, or a left ventricular end systolic diameter (LV-ESD) above the median were predictive for AVR assignment (table 4). Conversely, renal impairment reduced the likelihood of an asymptomatic patient being assigned to AVR.

\section{DISCUSSION}

In the present study, almost a quarter $(23.8 \%)$ of patients with severe symptomatic AS did not undergo AVR. Age $>80$ years, severe frailty and the comorbidities renal impairment (CCR $<50 \mathrm{~mL} / \mathrm{min}$ or dialysis) and concomitant $\mathrm{mitral} /$ tricuspid valve regurgitation were all found to be independent deterrents for AVR in this subpopulation. Further, the absence of dyspnoea and a larger AVA, lower MPG and lower $\mathrm{V}_{\max }$ despite severe AS were associated with a medical treatment decision. Interestingly, symptomatic patients with a lower surgical risk were also less likely to be assigned to AVR. Conversely, over one-third $(36.3 \%)$ of asymptomatic individuals with no predesignated indication for AVR were assigned to undergo treatment (with TAVI planned in over half of these cases); very few variables were associated with this treatment decision.

Treatment denial and not adhering to guideline recommendations for patients with symptomatic AS is not uncommon (range 21\%-41\%), ${ }^{510}$ and our results support these findings. Fortunately, the number of patients not being treated has reduced over time, which may be attributed to the adoption of TAVI as a treatment option for high-risk patients, as well as changes in decision-making by the heart team in many centres. ${ }^{11}$ Nevertheless, it is crucial to understand the variables 


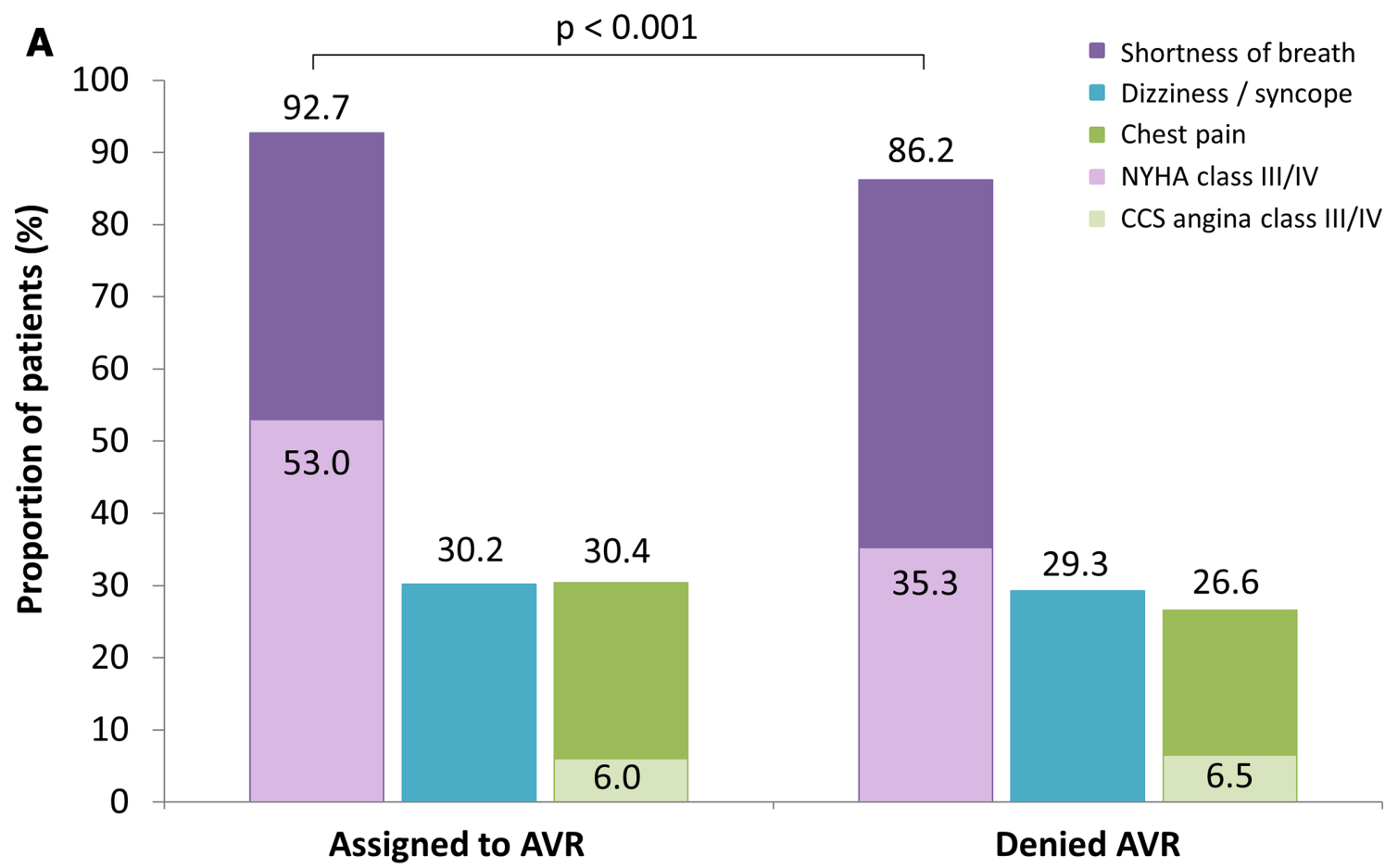

B

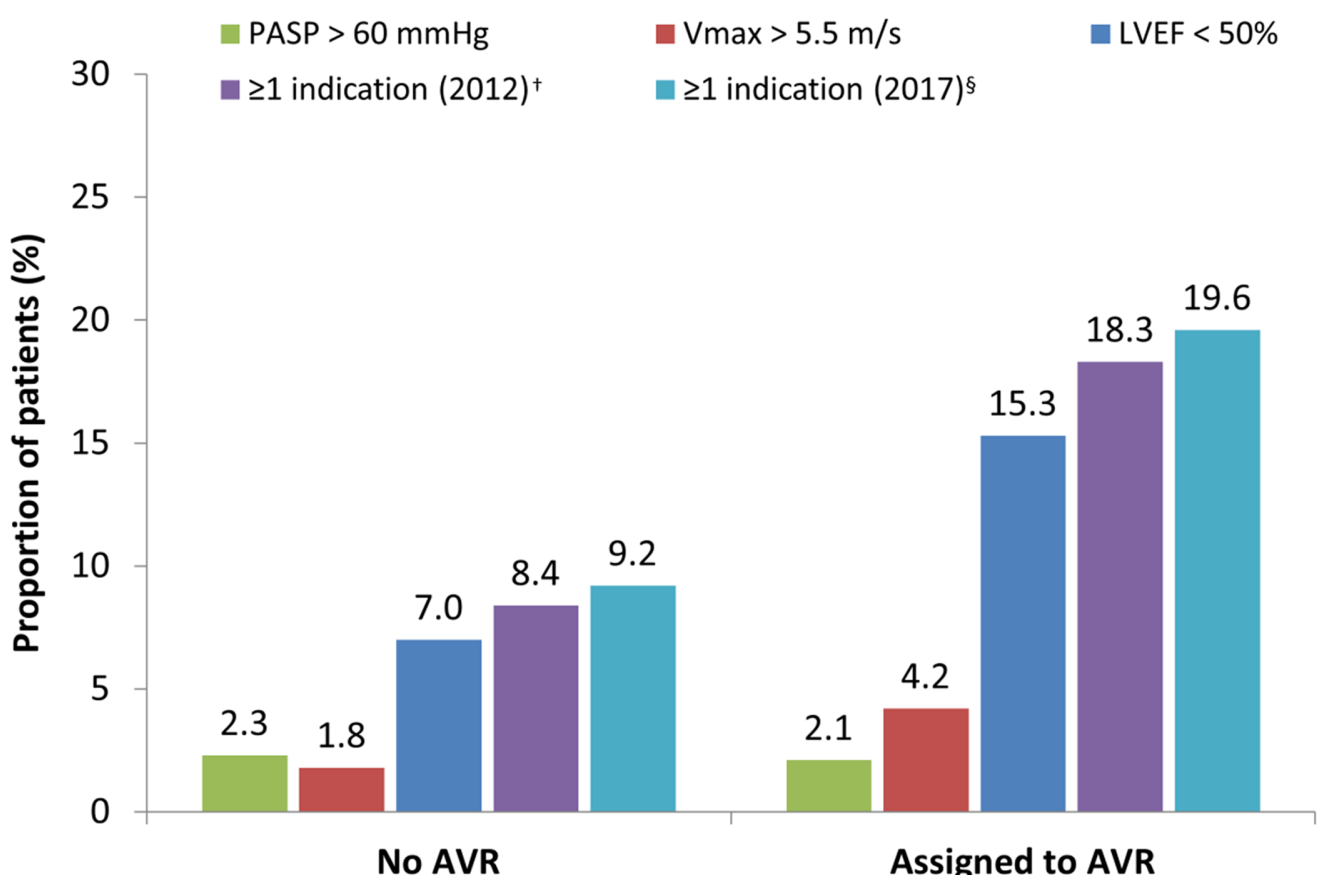

Figure 2 Impact of (A) symptoms in symptomatic* patients and (B) guideline recommendations in asymptomatic* patients on the decision to perform aortic valve replacement (AVR). CCS, Canadian Cardiovascular Society; LVEF, left ventricular ejection fraction; NYHA, New York Heart Association; PASP, pulmonary artery systolic pressure; $\mathrm{V}_{\text {max }}$, peak aortic valve (AV) jet velocity. *Symptomatic defined as having $\geq 1$ of the following (presumed to be AS-related): chest pain, shortness of breath, dizziness on exertion/syncope. ${ }^{\dagger} \mathrm{V}_{\max }>5.5 \mathrm{~m} / \mathrm{s}$ and/or LVEF $<50 \% .{ }^{\S} \mathrm{V}_{\max }>5.5 \mathrm{~m} / \mathrm{s}$ and/or LVEF $<50 \%$ and/or PASP $>60 \mathrm{~mm} \mathrm{Hg}$.

associated with an active decision not to perform AVR in almost one-quarter of symptomatic patients, especially as the survival prospects associated with this strategy are poor. $^{12}$

Older age and more severe left ventricular dysfunction were found to be key drivers of SAVR denial in patients with symptomatic AS enrolled in the Euro Heart Survey, ${ }^{4}$ likely due to the higher surgical risk associated with interventions in these patients. ${ }^{13}$ While this study found that age was associated with AVR denial, both a smaller AVA and a lower LVEF appeared to increase the likelihood of intervention by nearly twofold. This is probably a result 
Table 2 Echocardiographic parameters

\begin{tabular}{|c|c|c|c|c|c|c|}
\hline & $\begin{array}{l}\text { Symptomatic* pat } \\
\text { decision } \\
(n=1608)\end{array}$ & tients with tre & & $\begin{array}{l}\text { Asymptoma } \\
\text { decision } \\
(\mathrm{n}=392)\end{array}$ & ic* patients with tre & eatment \\
\hline & $\begin{array}{l}\text { Assigned to AVR } \\
\mathrm{n}=1225 \\
\mathrm{n}(\%) \text { or } \\
\text { mean } \pm \mathrm{SD}\end{array}$ & $\begin{array}{l}\text { Denied AVR } \\
\mathrm{n}=383 \\
\mathrm{n}(\%) \text { or } \\
\text { mean } \pm S D\end{array}$ & $P$ value & $\begin{array}{l}\text { No AVR } \\
\mathrm{n}=238 \\
\mathrm{n}(\%) \text { or } \\
\text { mean } \pm \text { SD }\end{array}$ & $\begin{array}{l}\text { Assigned to AVR } \\
\mathrm{n}=154 \\
\mathrm{n}(\%) \text { or } \\
\text { mean } \pm \mathrm{SD}\end{array}$ & $P$ value \\
\hline Indexed AVA $\left(\mathrm{cm}^{2} / \mathrm{m}^{2}\right)$ & $0.38 \pm 0.10$ & $0.41 \pm 0.12$ & $<0.001$ & $0.44 \pm 0.11$ & $0.40 \pm 0.10$ & 0.001 \\
\hline $\mathrm{V}_{\max }(\mathrm{m} / \mathrm{s})$ & $4.33 \pm 0.67$ & $4.23 \pm 0.68$ & 0.014 & $4.29 \pm 0.56$ & $4.42 \pm 0.62$ & 0.034 \\
\hline Mean AV gradient $(\mathrm{mm} \mathrm{Hg})$ & $48.0 \pm 14.6$ & $44.6 \pm 15.4$ & $<0.001$ & $47.0 \pm 12.7$ & $48.8 \pm 14.4$ & 0.211 \\
\hline LVEF (\%) & $54.9 \pm 12.0$ & $57.1 \pm 12.5$ & 0.002 & $61.4 \pm 9.5$ & $57.1 \pm 10.8$ & $<0.001$ \\
\hline PASP $(\mathrm{mm} \mathrm{Hg})$ & $39.9 \pm 12.9$ & $39.4 \pm 14.1$ & 0.613 & $35.0 \pm 10.8$ & $37.6 \pm 10.7$ & 0.047 \\
\hline $\begin{array}{l}\text { AVA }<1 \mathrm{~cm}^{2} \text { and mean AV gradient } \\
<40 \mathrm{mmHg}\end{array}$ & 280/1199 (23.4) & 119/373 (31.9) & 0.001 & 48/236 (20.3) & $26 / 152(17.1)$ & 0.429 \\
\hline Aortic regurgitation grade III/IV & $82 / 1166(7.0)$ & 28/367 (7.6) & 0.699 & $27 / 224(12.1)$ & $10 / 149(6.7)$ & 0.091 \\
\hline Mitral regurgitation grade III/IV & 109/1199 (9.1) & $65 / 371(17.5)$ & $<0.001$ & 19/224 (8.5) & 6/153 (3.9) & 0.081 \\
\hline Mitral stenosis grade III/IV & $19 / 1137(1.7)$ & $5 / 348(1.4)$ & 0.762 & $5 / 208(2.4)$ & $3 / 146(2.1)$ & 1.000 \\
\hline Tricuspid regurgitation grade III/IV & $76 / 1157(6.6)$ & 45/358 (12.6) & $<0.001$ & $13 / 221(5.9)$ & $6 / 149(4.0)$ & 0.428 \\
\hline LVH† & $759 / 1214(62.5)$ & 227/367 (61.9) & 0.817 & $136 / 231(58.9)$ & $88 / 152(57.9)$ & 0.849 \\
\hline Relative wall thickness & $0.52 \pm 0.15$ & $0.55 \pm 0.16$ & 0.011 & $0.53 \pm 0.15$ & $0.52 \pm 0.14$ & 0.383 \\
\hline LV mass $(\mathrm{g})$ & $243.2 \pm 75.9$ & $232.8 \pm 82.5$ & 0.047 & $237.7 \pm 72.6$ & $252.2 \pm 76.6$ & 0.091 \\
\hline Indexed LV mass $\left(\mathrm{g} / \mathrm{m}^{2}\right)$ & $131.3 \pm 39.9$ & $133.0 \pm 44.3$ & 0.546 & $129.8 \pm 39.0$ & $137.0 \pm 39.1$ & 0.121 \\
\hline LV-ESD (mm) & $33.0 \pm 11.3$ & $29.9 \pm 9.2$ & $<0.001$ & $28.2 \pm 6.2$ & $31.2 \pm 8.3$ & 0.001 \\
\hline LV-EDD (mm) & $48.8 \pm 9.9$ & $46.0 \pm 7.9$ & $<0.001$ & $46.5 \pm 7.0$ & $48.4 \pm 7.9$ & 0.022 \\
\hline IVS (mm) & $13.6 \pm 2.5$ & $13.8 \pm 2.8$ & 0.320 & $13.9 \pm 2.8$ & $13.9 \pm 2.5$ & 0.984 \\
\hline PW (mm) & $12.1 \pm 2.3$ & $12.1 \pm 2.7$ & 0.979 & $12.0 \pm 2.2$ & $12.1 \pm 2.2$ & 0.759 \\
\hline LVEF $<30 \%$ & 40/1168 (3.4) & $9 / 365(2.5)$ & 0.363 & $2 / 229(0.9)$ & 4/144 (2.8) & 0.211 \\
\hline LVEF $\geq 50 \%$ and PASP $<55 \mathrm{~mm} \mathrm{Hg}$ & 743/1094 (67.9) & $238 / 340(70.0)$ & 0.470 & 189/211 (89.6) & $108 / 138(78.3)$ & 0.004 \\
\hline
\end{tabular}

*Symptomatic defined as having $\geq 1$ of the following (presumed to be AS related): chest pain, shortness of breath, dizziness on exertion/ syncope.

$\dagger>12 \mathrm{~mm}$ in thickness.

AV, aortic valve; AVA, aortic valve area; IVS, interventricular septum; LV, left ventricular; LV-EDD, left ventricular end diastolic diameter; LVEF, left ventricular ejection fraction; LV-ESD, left ventricular end systolic diameter; PASP, pulmonary artery systolic pressure; PW, posterior wall; $\mathrm{V}_{\max }$, peak AV jet velocity.

of recent evidence demonstrating the substantial functional recovery and mortality benefit from AVR interventions in patients with poor left ventricular function, ${ }^{13} 14$ with TAVI shown to be particularly safe in this population. ${ }^{1516}$ In this context and given the often exacerbated symptoms in patients with a lower $\mathrm{LVEF}^{17}$ poorer echocardiographic valve parameters may actually be viewed as an incentive for AVR, with a greater improvement in quality of life to be gained for the interventional risk and a better risk-benefit ratio. This is supported by the fact that dyspnoea appeared to be a major driver of a positive AVR decision. However, waiting for a deterioration in echocardiographic parameters and symptoms before scheduling AVR treatment increases the risk of sudden cardiac death. ${ }^{18}$

More recently, comorbidity has been highlighted as a reason for non-assignment of symptomatic patients to SAVR. ${ }^{19}$ In this study, renal impairment was identified as an independent predictor of AVR denial in symptomatic patients, likely because pre-existing chronic kidney disease is strongly associated with worse outcomes following TAVI. ${ }^{20}$ In contrast to medical management, AVR in haemodialysis patients has been shown to result in a significantly lower long-term mortality risk. ${ }^{21}$ Furthermore, TAVI may improve renal function, ${ }^{22}$ and reduce rates of in-hospital mortality compared with SAVR. ${ }^{23}$ The presence of concomitant valvular disease is a substantial factor influencing the decision to deny TAVI. ${ }^{24}{ }^{25}$ Significant concomitant mitral/tricuspid valve regurgitation were identified as independent predictors of AVR denial in symptomatic patients in our study. Both mitral and tricuspid regurgitation are known to affect functional status and prognosis in patients with AS undergoing AVR. ${ }^{26}{ }^{27}$ There is little evidence, however, to support combined or sequential procedures to address concomitant valve conditions and modify this risk. ${ }^{27}$ As such, 
Table 3 Baseline predictors of AVR denial in symptomatic* patients with decision $(\mathrm{N}=1608)$

\begin{tabular}{|c|c|c|c|c|}
\hline & Univariate OR (95\% Cl) & Univariate $p$ value & Multivariate $†$ OR $(95 \%$ CI) & Multivariate $\dagger p$ value \\
\hline $\begin{array}{l}\text { Referring by cardio (vs other referring } \\
\text { physician) }\end{array}$ & 0.791 (0.605 to 1.034$)$ & 0.086 & 0.594 (0.426 to 0.828$)$ & 0.002 \\
\hline Age $>$ versus $\leq 80$ years & $1.562(1.240$ to 1.968$)$ & $<0.001$ & 1.390 (1.041 to 1.858$)$ & 0.026 \\
\hline Severe frailty & 2.349 (1.432 to 3.855$)$ & 0.001 & 2.036 (1.096 to 3.781$)$ & 0.024 \\
\hline EuroSCORE II> versus $\leq 2.39 \%$ & 1.051 (0.833 to 1.327$)$ & 0.676 & $0.673(0.487$ to 0.930$)$ & 0.016 \\
\hline \multicolumn{5}{|l|}{ Comorbidities } \\
\hline Renal impairmentł & 1.679 (1.297 to 2.172$)$ & $<0.001$ & 1.466 (1.071 to 2.007$)$ & 0.017 \\
\hline COPD & $1.463(1.055$ to 2.030$)$ & 0.023 & 1.450 (0.955 to 2.202) & 0.081 \\
\hline Diabetes§ & $1.040(0.697$ to 1.551$)$ & 0.847 & 1.343 (0.828 to 2.178$)$ & 0.232 \\
\hline Endocarditis & $3.222(0.802$ to 12.943$)$ & 0.099 & 2.198 (0.476 to 10.157$)$ & 0.313 \\
\hline 2-year life expectancy $<25 \% \emptyset$ & $1.614 ;(1.078$ to 2.418$)$ & 0.020 & 0.779 (0.439 to 1.382$)$ & 0.393 \\
\hline \multicolumn{5}{|l|}{ Cardiac-related symptoms } \\
\hline Chest pain & 0.831 (0.640 to 1.081$)$ & 0.168 & 0.780 (0.566 to 1.076$)$ & 0.130 \\
\hline Shortness of breath & $0.493(0.343$ to 0.710$)$ & $<0.001$ & $0.568(0.358$ to 0.900$)$ & 0.016 \\
\hline Dizziness on exertion/syncope & 0.961 (0.736 to 1.254$)$ & 0.770 & $0.788(0.566$ to 1.096$)$ & 0.157 \\
\hline NYHA class III/IV & 0.484 (0.381 to 0.615$)$ & $<0.001$ & $0.452(0.333$ to 0.613$)$ & $<0.001$ \\
\hline Angina class III/IV & 1.090 (0.665 to 1.785$)$ & 0.733 & 1.068 (0.582 to 1.959$)$ & 0.832 \\
\hline \multicolumn{5}{|l|}{ Echocardiographic parameters } \\
\hline Indexed AVA $\leq$ versus $>0.39 \mathrm{~cm}^{2} / \mathrm{m}^{2}$ & 0.604 (0.471 to 0.775$)$ & $<0.001$ & 0.566 (0.416 to 0.771$)$ & $<0.001$ \\
\hline$V_{\max }>$ versus $\leq 4.3 \mathrm{~m} / \mathrm{s}$ & $0.813(0.637$ to 1.037$)$ & 0.096 & 1.207 (0.795 to 1.832$)$ & 0.378 \\
\hline $\begin{array}{l}\text { Mean AV gradient }>\text { versus } \leq 45.0 \mathrm{~mm} \\
\mathrm{Hg}\end{array}$ & 0.738 (0.584 to 0.931$)$ & 0.010 & 0.776 (0.511 to 1.178$)$ & 0.234 \\
\hline LVEF $\leq$ versus $>58 \%$ & 0.828 (0.655 to 1.048$)$ & 0.116 & 0.511 (0.382 to 0.683$)$ & $<0.001$ \\
\hline PASP $>$ versus $\leq 37.0 \mathrm{~mm} \mathrm{Hg}$ & 1.146 (0.894 to 1.468$)$ & 0.282 & 0.898 (0.664 to 1.214$)$ & 0.485 \\
\hline $\begin{array}{l}\text { AVA }<1 \mathrm{~cm}^{2} \text { and mean AV gradient } \\
<40 \mathrm{~mm} \mathrm{Hg}\end{array}$ & 1.538 (1.191 to 1.985$)$ & 0.001 & 1.371 (0.915 to 2.054) & 0.126 \\
\hline Aortic regurgitation grade III/IV & 1.092 (0.699 to 1.706$)$ & 0.699 & $0.886(0.520$ to 1.509$)$ & 0.656 \\
\hline Mitral regurgitation grade III/IV & 2.124 (1.524 to 2.961$)$ & $<0.001$ & 1.995 (1.299 to 3.064) & 0.002 \\
\hline Tricuspid regurgitation grade III/IV & 2.045 (1.385 to 3.019$)$ & $<0.001$ & 2.029 (1.246 to 3.304$)$ & 0.004 \\
\hline LV-ESD $>$ versus $\leq 30.0 \mathrm{~mm}$ & 0.586 (0.440 to 0.782$)$ & $<0.001$ & 0.693 (0.476 to 1.009$)$ & 0.056 \\
\hline LV-EDD $>$ versus $\leq 47.0 \mathrm{~mm}$ & $0.606(0.471$ to 0.780$)$ & $<0.001$ & $0.773(0.564$ to 1.059$)$ & 0.108 \\
\hline IVS $>$ versus $\leq 13.3 \mathrm{~mm}$ & 1.202 (0.937 to 1.542$)$ & 0.148 & 1.350 (1.003 to 1.817$)$ & 0.048 \\
\hline $\mathrm{PW}>$ versus $\leq 12.0 \mathrm{~mm}$ & 0.957 (0.733 to 1.249$)$ & 0.745 & $0.850(0.622$ to 1.163$)$ & 0.311 \\
\hline Relative wall thickness $>$ versus $\leq 0.51$ & 1.183 (0.908 to 1.541$)$ & 0.214 & $1.063(0.778$ to 1.454$)$ & 0.701 \\
\hline LV mass $>$ versus $\leq 233.9 \mathrm{~g}$ & 0.777 (0.596 to 1.012$)$ & 0.061 & 1.047 (0.760 to 1.443$)$ & 0.778 \\
\hline LV mass indexed $>$ versus $\leq 126.3 \mathrm{~g} / \mathrm{m}^{2}$ & $1.149(0.870$ to 1.518$)$ & 0.327 & $1.330(0.956$ to 1.851$)$ & 0.091 \\
\hline LVEF $<50 \%$ and PASP $\geq 55 \mathrm{~mm} \mathrm{Hg}$ & 0.907 (0.696 to 1.182$)$ & 0.470 & 0.815 (0.560 to 1.188$)$ & 0.288 \\
\hline
\end{tabular}

All continuous variables were converted to binary predictors using the median of the overall study population as a cut off.

*Symptomatic defined as having $\geq 1$ of the following (presumed to be AS related): chest pain, shortness of breath, dizziness on exertion/ syncope.

†Adjusted for age, severefrailty, renal insufficiency, COPD, $\mathrm{V}_{\max }$, mean AV gradient, LVEF, mitral regurgitation grade III/IV and tricuspid regurgitation grade III/IV.

$\ddagger$ Creatinine clearance rate $<50 \mathrm{~mL} / \mathrm{min}$ or dialysis.

§Insulin dependent.

१2-year life expectancy< $25 \%$ was assessed by the dedicated nurses and physicians.

AV, aortic valve; AVA, aortic valve area; AVR, aortic valve replacement; COPD, chronic obstructive pulmonary disease; IVS, interventricular septum; LV, left ventricular; LV-EDD, left ventricular end diastolic diameter; LVEF, left ventricular ejection fraction; LV-ESD, left ventricular end systolic diameter; NYHA, New York Heart Association; PASP, pulmonary artery systolic pressure; PW, posterior wall; $\mathrm{V}_{\max }$, peak AV jet velocity. 


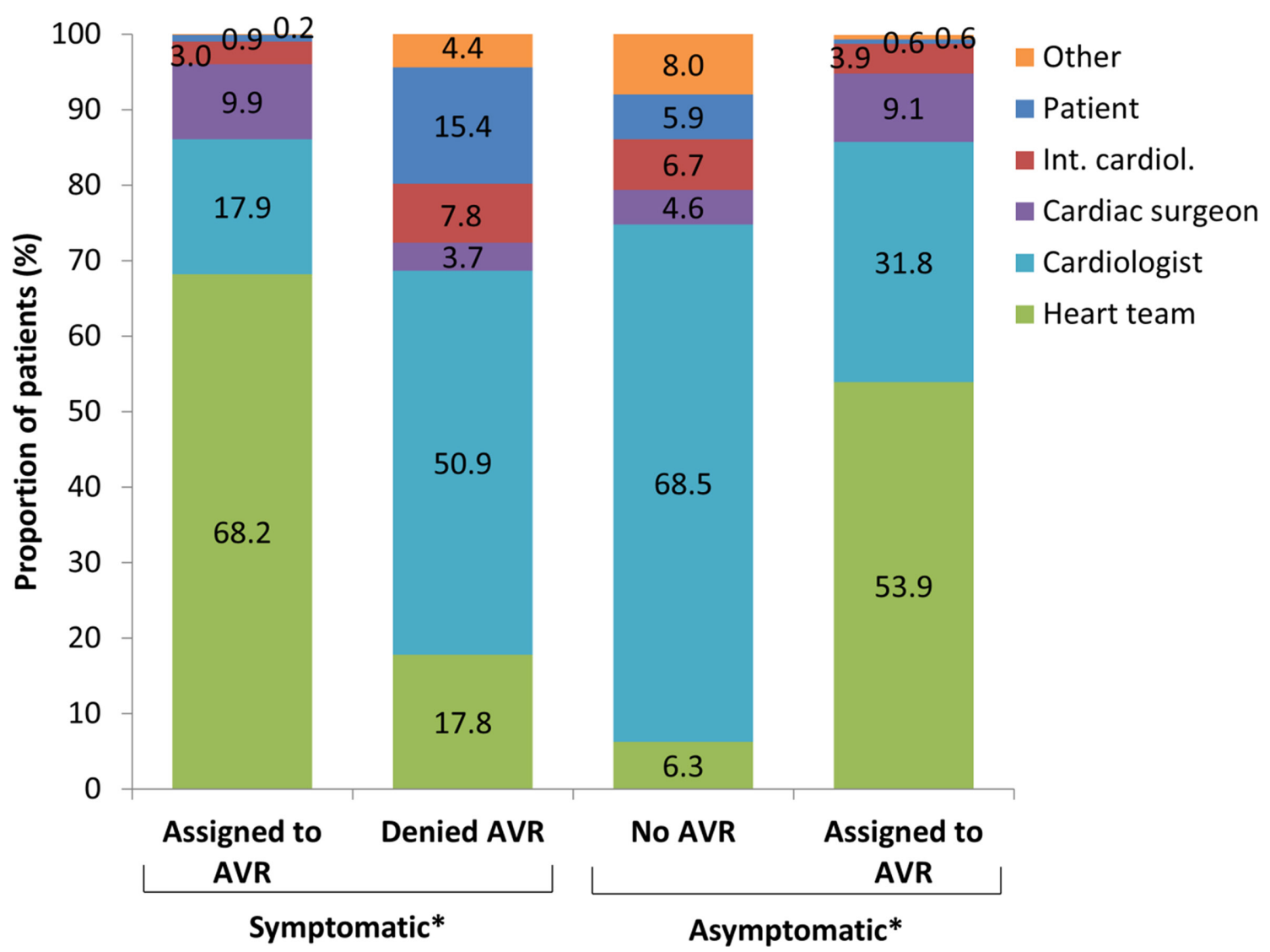

Figure 3 Entity responsible for treatment decision. AVR, aortic valve replacement; int. cardiol, interventional cardiologist. *Symptomatic defined as having $\geq 1$ of the following (presumed to be aortic stenosis related): chest pain, shortness of breath, dizziness on exertion/syncope.

it is natural that mitral and tricuspid regurgitation are current deterrents to AVR. Existing knowledge gaps need to be addressed. Frailty is consistently associated with death and disability after TAVI and SAVR, ${ }^{28}$ and this study showed that severe frailty was independently associated with AVR denial in symptomatic patients. Indeed, both 2012 and 2017 guidelines identify this variable as a key consideration for SAVR versus TAVI decision-making. ${ }^{2}$

Guidelines recognise the limitations and inaccuracies of classical surgical risk scores when assessing a patient for either intervention, although highlighting the utility of scores to predict general trends in outcomes. Interestingly, after adjustment for potentially confounding variables, a lower surgical risk score appeared to translate into a higher likelihood of AVR denial in the present population. This appears paradoxical, especially given that prior studies have noted a clear and logical association between higher EuroSCORE II values and poorer postinterventional outcomes. ${ }^{29}$ Given the large number of variables entered into the regression, this finding may merely represent a statistical error, which merits further exploration.

In this study, the patient was responsible for the treatment decision in $15 \%$ of symptomatic cases not assigned to AVR. It is assumed that all patients were fully informed when making such a choice, but education programmes should stress the relative futility of medical management compared with AVR. ${ }^{30}$ Patient preference is likely to be influenced by the responsible practitioner, cardiologist and heart team. Strikingly, over half of the decisions not to perform AVR in symptomatic patients were taken by a cardiologist, with the heart team involved in just $18 \%$ of cases. This is a clear deviation from guideline recommendations, which state that the heart team should be integral to the clinical decision-making process. ${ }^{2}$ Indeed, over two-thirds of positive AVR decisions were made by the heart team, suggesting that a comprehensive expert and multidisciplinary review took place, which may have resulted in a higher proportion of symptomatic patients not undergoing AVR being assigned to such an intervention. Increasing the awareness of the importance of the heart team's perspective, therefore, may increase the proportion of patients benefitting from AVR.

According to 2017 guidelines, AVR is only indicated in asymptomatic patients under specific circumstances ${ }^{2}$; present data support the use of SAVR when a patient has a LVEF $<50 \%$; a $\mathrm{V}_{\max }>5 \mathrm{~m} / \mathrm{s}$ or pressure difference of $>60 \mathrm{~mm} \mathrm{Hg}$; an abnormal exercise test; rapid AS progression; or progressively increasing brain natriuretic peptide values. ${ }^{31}$ Furthermore, only SAVR and not TAVI is advocated in this population, given only very minimal evidence for the latter intervention. ${ }^{32}$ Despite this, onethird of asymptomatic individuals with no predesignated indication for AVR were assigned to treatment, over half 
Table 4 Baseline predictors of AVR assignment in asymptomatic* patients with decision ( $N=392)$

\begin{tabular}{|c|c|c|c|c|}
\hline & $\begin{array}{l}\text { Univariate OR } \\
(95 \% \mathrm{Cl})\end{array}$ & $\begin{array}{l}\text { Univariate } p \\
\text { value }\end{array}$ & $\begin{array}{l}\text { Multivariate† OR } \\
(95 \% \mathrm{Cl})\end{array}$ & $\begin{array}{l}\text { Multivariate† } \\
\text { p value }\end{array}$ \\
\hline Referring by cardio (vs other referring physician) & 1.213 (0.735 to 2.002$)$ & 0.450 & 1.226 (0.678 to 2.216$)$ & 0.501 \\
\hline Age $>$ versus $\leq 80$ years & $0.833(0.546$ to 1.271$)$ & 0.396 & 0.695 (0.409 to 1.178$)$ & 0.176 \\
\hline Severe frailty & 0.584 (0.180 to 1.897$)$ & 0.371 & 0.586 (0.129 to 2.655$)$ & 0.488 \\
\hline EuroSCORE II>versus $\leq 2.39 \%$ & 0.914 (0.526 to 1.588$)$ & 0.749 & 0.899 (0.431 to 1.872$)$ & 0.775 \\
\hline \multicolumn{5}{|l|}{ Comorbidities } \\
\hline Renal impairmentł & 0.717 (0.401 to 1.279$)$ & 0.259 & 0.451 (0.204 to 0.998$)$ & 0.049 \\
\hline COPD & $1.382(0.521$ to 3.663$)$ & 0.515 & $1.588(0.484$ to 5.210$)$ & 0.445 \\
\hline Diabetes§ & 0.406 (0.148 to 1.119$)$ & 0.081 & $0.404(0.119$ to 1.378$)$ & 0.148 \\
\hline Endocarditis & n.a. & n.a. & n.a. & n.a. \\
\hline 2-year life expectancy $<25 \% \emptyset$ & 1.843 (0.483 to 7.035$)$ & 0.371 & 0.897 (0.169 to 4.768$)$ & 0.899 \\
\hline \multicolumn{5}{|l|}{ Echocardiographic parameters } \\
\hline Indexed AVA $\leq$ versus $>0.39 \mathrm{~cm}^{2} / \mathrm{m}^{2}$ & 2.169 (0.398 to 3.366$)$ & 0.001 & 1.709 (1.012 to 2.886$)$ & 0.045 \\
\hline$V_{\max }>$ versus $\leq 4.3 \mathrm{~m} / \mathrm{s}$ & 1.592 (1.045 to 2.426) & 0.030 & $1.227(0.630$ to 2.392$)$ & 0.547 \\
\hline Mean AV gradient >versus $\leq 45.0 \mathrm{~mm} \mathrm{Hg}$ & 1.493 (0.992 to 2.247) & 0.055 & 1.434 (0.741 to 2.774$)$ & 0.285 \\
\hline LVEF $\leq$ versus $>58 \%$ & 1.758 (1.152 to 2.681$)$ & 0.009 & 2.815 (1.698 to 4.666$)$ & $<0.001$ \\
\hline PASP $>$ versus $\leq 37.0 \mathrm{~mm} \mathrm{Hg}$ & 1.463 (0.917 to 2.333) & 0.110 & 1.593 (0.910 to 2.789) & 0.103 \\
\hline AVA $<1 \mathrm{~cm}^{2}$ and mean AV gradient $<40 \mathrm{~mm} \mathrm{Hg}$ & $0.808(0.477$ to 1.370$)$ & 0.429 & $0.960(0.452$ to 2.040$)$ & 0.915 \\
\hline Aortic regurgitation grade III/IV & $0.525(0.246$ to 1.119$)$ & 0.095 & $0.612(0.235$ to 1.592$)$ & 0.314 \\
\hline Mitral regurgitation grade III/IV & 0.440 (0.172 to 1.130$)$ & 0.088 & $0.460(0.143$ to 1.480$)$ & 0.193 \\
\hline Tricuspid regurgitation grade III/IV & 0.671 (0.249 to 1.808$)$ & 0.430 & 0.821 (0.211 to 3.194$)$ & 0.776 \\
\hline LV-ESD $>$ versus $\leq 30.0 \mathrm{~mm}$ & 2.251 (1.361 to 3.723$)$ & 0.002 & 2.303 (1.256 to 4.223$)$ & 0.007 \\
\hline LV-EDD >versus $\leq 47.0 \mathrm{~mm}$ & 1.691 (1.096 to 2.610$)$ & 0.018 & $1.358(0.807$ to 2.286$)$ & 0.249 \\
\hline IVS>versus $\leq 13.3 \mathrm{~mm}$ & 1.007 (0.649 to 1.563$)$ & 0.976 & 0.839 (0.496 to 1.421$)$ & 0.514 \\
\hline $\mathrm{PW}>$ versus $\leq 12.0 \mathrm{~mm}$ & $1.140(0.718$ to 1.810$)$ & 0.577 & $1.187(0.679$ to 2.076$)$ & 0.547 \\
\hline Relative wall thickness $>$ versus $\leq 0.51$ & 0.820 (0.522 to 1.289$)$ & 0.390 & 0.917 (0.537 to 1.565$)$ & 0.750 \\
\hline LV mass $>$ versus $\leq 233.9 \mathrm{~g}$ & $1.486(0.942$ to 2.345$)$ & 0.088 & $1.122(0.658$ to 1.914$)$ & 0.673 \\
\hline LV mass indexed $>$ versus $\leq 126.3 \mathrm{~g} / \mathrm{m}^{2}$ & 1.364 (0.858 to 2.168$)$ & 0.190 & 1.043 (0.609 to 1.784$)$ & 0.879 \\
\hline LVEF $<50 \%$ and PASP $\geq 55 \mathrm{~mm} \mathrm{Hg}$ & 2.386 (1.311 to 4.343$)$ & 0.004 & 1.543 (0.689 to 3.455$)$ & 0.292 \\
\hline
\end{tabular}

All continuous variableswere converted to binary predictors using the median of the overall studypopulation as a cut off.

*Symptomatic defined as having $\geq 1$ of the following (presumed to be AS related): chest pain, shortness of breath, dizziness on exertion/ syncope.

†Adjusted for age, diabetes, atrial fibrillation, mean AV gradient, LVEF, PASP, aortic regurgitation grade III/IV, and mitral regurgitation grade III/ IV.

$\ddagger$ Creatinine clearance rate $<50 \mathrm{~mL} /$ minor dialysis.

§Insulin dependent.

१2-year life expectancy $<25 \%$ was assessed by the dedicated nurses and physicians.

AS, aortic stenosis; AV, aortic valve; AVA, aortic valve area; AVR, aortic valve replacement; COPD, chronic obstructive pulmonary disease; IVS, interventricular septum; LV, left ventricular; LV-EDD, left ventricular end diastolic diameter; LVEF, left ventricular ejection fraction; LV-ESD, left ventricular end systolic diameter; PASP, pulmonary artery systolic pressure; PW, posterior wall.

of which were TAVI procedures. In terms of independent predictors, a lower AVA indexed and LVEF, a higher LV-ESD and an absence of renal impairment were associated with AVR assignment. While only LVEF is specifically stated in guidelines within the context of AS, LV-ESD is an indicator for intervention in various other valve-related conditions. ${ }^{12}$ The role of kidney insufficiency deterring invasive procedures has already been discussed.$^{20}$ As such, our data suggest that there are few specific characteristics that would influence a positive AVR decision in asymptomatic patients.

\section{LIMITATIONS}

Due to the post-hoc nature of the present analysis, several factors that may potentially have contributed to treatment decisions were not available. Exercise testing, markedly elevated natriuretic peptide levels or combined severe valve 
calcification and a rate of $\mathrm{V}_{\max }$ progression $\geq 0.3 \mathrm{~m} / \mathrm{s} /$ year may also have resulted in a class I or IIa indication for AVR in asymptomatic patients, ${ }^{12}$ though this information was not systematically recorded. This may explain a large number of the asymptomatic patients assigned to AVR (including TAVI). Moreover, we did not capture specific reasons for the denial of AVR in extreme risk or inoperable patients which would have required a specific questionnaire. Furthermore, a large number of factors were considered in the regression analyses; while this is defensible given that our aim was to provide a comprehensive view of the characteristics contributing to AVR decision-making, it also increases the potential for overfitting. Finally, while the Europe-wide nature of the present study is a clear strength, our findings may not be generalisable to other countries or regions outside of Europe, or to centres where not all AS management options are available. Nevertheless, the data provide an interesting snapshot into some of the behaviours and parameters likely contributing to treatment decisions in severe AS.

\section{CONCLUSION}

The present results illustrate that almost one-quarter of patients with symptomatic severe AS with guideline indications for AVR did not undergo valve replacement, despite the poor prognosis associated with a lack of intervention. In contrast, over one-third of asymptomatic patients were assigned to AVR, with very few specific characteristics associated with this choice. We conclude that there may be a considerable discrepancy between guideline-based recommendations and clinical practice decision-making in the treatment of AS. It appears as if guidelines may not fully capture the clinical spectrum of AS presentation and the individual patient need for an intervention or that unrequired AVRs may be being performed.

\section{Author affiliations}

${ }^{1}$ Department for Cardiology, Helios Clinic, Erfurt, Germany

${ }^{2}$ Department of Cardiology, Hear and Diabetes Center Bad Oeynhausen, Ruhr-

University of Bochum, Bad Oeynhausen, Germany

${ }^{3}$ University of Ottawa Heart Institute, Ottawa, Ontario, Canada

${ }^{4}$ James Cook University Hospital, Middlesbrough, UK

${ }^{5}$ Interventional Cardiology Unit, Hospital de la Santa Creu i Sant Pau, Barcelona, Catalunya, Spain

${ }^{6}$ Cardiology Department, AKH Celle, Celle, Niedersachsen, Germany

${ }^{7}$ Department of Cardiology and Angiology, University of Kiel, Kiel, Schleswig-

Holstein, Germany

${ }^{8}$ Department of Cardiovascular Surgery, Institute for Clinical and Experimental Medicine, Prague, Czech Republic

${ }^{9}$ Department of Cardiovascular Surgery, Second Faculty of Medicine, Charles University, Prague, Czech Republic

${ }^{10}$ Department of Cardiothoracic Surgery, Foundation IRCCS Policlinico S.Matteo, Pavia, Italy

${ }^{11}$ St Bartholomew's Hospital, London, UK

${ }^{12}$ University of Bari, Bari, Puglia, Italy

${ }^{13}$ University of Turin, Turin, Piemonte, Italy

${ }^{14} 4$ th Medical Department, Hietzing Hospital, Vienna, Austria

${ }^{15}$ Herzkatheterlabor Nymphenburg and Department of Cardiology, University of Munich, Munich, Bayern, Germany

${ }^{16}$ Division of Cardiology and URT CNR of IFC, University Magna Graecia, Catanzaro, Calabria, Italy

${ }^{17}$ Sapienza University of Rome, Rome, Italy

${ }^{18}$ Centre Hospital d'Annecy, Annecy, France
${ }^{19}$ Department of Cardiology, University Hospital Erlangen, Erlangen, Bayern, Germany

${ }^{20}$ University of Amsterdam, Amsterdam, Netherlands

${ }^{21}$ Institut für Pharmakologie und Präventive Medizin GmbH, Cloppenburg, Germany

${ }^{22}$ Edwards Lifesciences, Prague, Czech Republic

${ }^{23}$ Edwards Lifesciences, Nyon, Switzerland

${ }^{24}$ Queen Elizabeth Hospital \& Institute of Cardiovascular Sciences, University of Birmingham, Birmingham, UK

Twitter Antonio Serra @none, Matthias Lutz @MJLutz and Richard Paul Steeds @ Richard.Steeds

Acknowledgements Data were captured using the s4trials Software provided by Software for Trials Europe GmbH (Berlin, Germany). Funding provided by Edwards Lifesciences (Nyon, Switzerland) is acknowledged.

Contributors All authors have participated in the work. RPS, DM-Z, NF, JK, MT and PB were involved in the conception and design of the project. AL and PB drafted the manuscript and all other authors revised the article for important intellectual content. All authors gave final approval and agree to be accountable for all aspects of work ensuring integrity and accuracy.

Funding This work was supported with a research grant provided by Edwards Lifesciences (Nyon, Switzerland) to the Institute for Pharmacology and Preventive Medicine (IPPMed), Cloppenburg, Germany.

Competing interests Peter Bramlage received research funding from Edwards Lifesciences, Nyon, Switzerland. Norbert Frey, Rick Steeds and David MessikaZeitoun have received honoraria for advisory board meetings and Tanja Rudolph speakers' honoraria from Edwards Lifesciences. The institutions of these three and those of the remaining authors representing study centres have received funding for employing a study nurse.

Patient consent for publication Not required.

Ethics approval The study was approved by the independent ethics review board at each participating institution and carried out in accordance with the Declaration of Helsinki.

Provenance and peer review Not commissioned; externally peer reviewed.

Data availability statement Data are available from the corresponding author upon reasonable request.

Open access This is an open access article distributed in accordance with the Creative Commons Attribution Non Commercial (CC BY-NC 4.0) license, which permits others to distribute, remix, adapt, build upon this work non-commercially, and license their derivative works on different terms, provided the original work is properly cited, appropriate credit is given, any changes made indicated, and the use is non-commercial. See: http://creativecommons.org/licenses/by-nc/4.0/.

ORCID iDs

David Messika-Zeitoun http://orcid.org/0000-0002-6278-5670

Peter Bramlage http://orcid.org/0000-0003-4970-2110

Richard Paul Steeds http://orcid.org/0000-0001-5687-2535

\section{REFERENCES}

1 Vahanian A, Alfieri O. Guidelines on the management of valvular heart disease (version 2012)The Joint Task Force on the Management of Valvular Heart Disease of the European Society of Cardiology (ESC) and the European Association for Cardio-Thoracic Surgery (EACTS). Eur Heart $J$ 2012;33:2451-96.

2 Baumgartner H, Falk V, Bax JJ, et al. 2017 ESC/EACTS guidelines for the management of valvular heart disease. Eur Heart $J$ 2017;38:2739-91.

3 Kang D-H, Park S-J, Lee S-A, et al. Early surgery or conservative care for asymptomatic aortic stenosis. $N$ Engl J Med 2020;382:111-9.

4 lung B, Cachier A, Baron G, et al. Decision-Making in elderly patients with severe aortic stenosis: why are so many denied surgery? Eur Heart J 2005;26:2714-20.

5 Bouma BJ, van Den Brink RB, van Der Meulen JH, et al. To operate or not on elderly patients with aortic stenosis: the decision and its consequences. Heart 1999;82:143-8.

6 Frey N, Steeds RP, Serra A, et al. Quality of care assessment and improvement in aortic stenosis - rationale and design of a multicentre registry (IMPULSE). BMC Cardiovasc Disord 2017;17:5. 
7 Frey N, Steeds RP, Rudolph TK, et al. Symptoms, disease severity and treatment of adults with a new diagnosis of severe aortic stenosis. Heart 2019;105:1709-16.

8 Steeds RP, Lutz M, Thambyrajah J, et al. Facilitated data relay and effects on treatment of severe aortic stenosis in Europe. J Am Heart Assoc 2019;8:e013160.

9 Katz S, Downs TD, Cash HR, et al. Progress in development of the index of ADL. Gerontologist 1970;10:20-30.

10 lung B, Delgado V, Rosenhek R, et al. Contemporary presentation and management of valvular heart disease: the EURObservational research programme valvular heart disease II survey. Circulation 2019;140:1156-69.

11 Ludman PF, Van Domburg R. The scientific value of TAVI surveys: insights and perspectives from European centres and European patients. Eurolntervention 2016;12:823-6.

12 Ramaraj R, Sorrell VL. Degenerative aortic stenosis. BMJ 2008;336:550-5.

13 Elmariah S, Palacios IF, McAndrew T, et al. Outcomes of transcatheter and surgical aortic valve replacement in high-risk patients with aortic stenosis and left ventricular dysfunction: results from the placement of aortic transcatheter valves (partner) trial (cohort a). Circ Cardiovasc Interv 2013;6:604-14.

14 Schymik G, Tzamalis P, Herzberger V, et al. Transcatheter aortic valve implantation in patients with a reduced left ventricular ejection fraction: a single-centre experience in 2000 patients (TAVIK registry). Clin Res Cardiol 2017;106:1018-25.

15 Pilgrim T, Wenaweser P, Meuli F, et al. Clinical outcome of high-risk patients with severe aortic stenosis and reduced left ventricular ejection fraction undergoing medical treatment or TAVI. PLoS One 2011;6:e27556.

16 Clavel MA, Webb JG, Rodés-Cabau J, et al. Comparison between transcatheter and surgical prosthetic valve implantation in patients with severe aortic stenosis and reduced left ventricular ejection fraction. Circulation 2010;122:1928-36.

17 Dahl JS, Eleid MF, Michelena HI, et al. Effect of left ventricular ejection fraction on postoperative outcome in patients with severe aortic stenosis undergoing aortic valve replacement. Circ Cardiovasc Imaging 2015;8:e002917.

18 Carabello BA, Shah PK. Aortic valve replacement should be operated on before symptom onset. Circulation 2012;126:112-7.

19 Badran AA, Vohra HA, Livesey SA. Unoperated severe aortic stenosis: decision making in an adult UK-based population. Ann $R$ Coll Surg Engl 2012;94:416-21.
20 Ifedili IA, Bolorunduro O, Bob-Manuel T, et al. Impact of pre-existing kidney dysfunction on outcomes following transcatheter aortic valve replacement. Curr Cardiol Rev 2017;13:283-92.

21 Kawase Y, Taniguchi T, Morimoto T, et al. Severe aortic stenosis in dialysis patients. J Am Heart Assoc 2017;6:e004961.

22 Keleș T, Ayhan H, Durmaz T, et al. Improvement in renal functions with transcatheter aortic valve implantation. J Geriatr Cardiol 2013;10:C232-3.

23 Alqahtani F, Aljohani S, Boobes K, et al. Outcomes of transcatheter and surgical aortic valve replacement in patients on maintenance dialysis. Am J Med 2017;130:1464.e1-1464.e11.

24 Nuis RJ, Dager AE, van der Boon RM, et al. Patients with aortic stenosis referred for TAVI: treatment decision, in-hospital outcome and determinants of survival. Neth Heart J 2012;20:16-23.

25 Boureau AS, Trochu JN, Colliard C, et al. Determinants in treatment decision-making in older patients with symptomatic severe aortic stenosis. Maturitas 2015;82:128-33.

26 Bedogni F, Latib A, De Marco F, et al. Interplay between mitral regurgitation and transcatheter aortic valve replacement with the CoreValve Revalving system: a multicenter registry. Circulation 2013;128:2145-53

27 Lindman BR, Maniar HS, Jaber WA, et al. Effect of tricuspid regurgitation and the right heart on survival after transcatheter aortic valve replacement: insights from the placement of aortic transcatheter valves II inoperable cohort. Circ Cardiovasc Interv 2015:8:e002073.

28 Afilalo J, Lauck S, Kim DH, et al. Frailty in Older Adults Undergoing Aortic Valve Replacement: The FRAILTY-AVR Study. J Am Coll Cardiol 2017;70:689-700.

29 Biancari F, Juvonen T, Onorati F, et al. Meta-Analysis on the performance of the EuroSCORE II and the Society of thoracic surgeons scores in patients undergoing aortic valve replacement. $J$ Cardiothorac Vasc Anesth 2014;28:1533-9.

30 Herrmann HC, Pibarot P, Hueter I, et al. Predictors of mortality and outcomes of therapy in low-flow severe aortic stenosis: a placement of aortic transcatheter valves (partner) trial analysis. Circulation 2013;127:2316-26.

31 Katayama M, Chaliki HP. Diagnosis and management of patients with asymptomatic severe aortic stenosis. World J Cardiol 2016;8:192-200.

32 Schymik G. Early and late outcomes after TAVI in asymptomatic patients with severe aortic stenosis from the source $X T$ registry. Eurolntervention, 2014. 